\title{
Deaths in Patients with Pulmonary Tuberculosis: An Analysis of a Chest Diseases Hospital in Istanbul, Turkey
}

\author{
Zafer Kartaloglu Ahmet Ilvan Erol Kilic Oguzhan Okutan \\ Kamil Cerrahoglu Faruk Ciftci \\ GATA Camlica Chest Diseases Hospital, Istanbul, Turkey
}

Key Words

Tuberculosis · Fatality $\cdot$ Mortality $\cdot$ Death

\begin{abstract}
Objective: To evaluate the medical records of patients with pulmonary tuberculosis in order to determine the inhospital mortality rate. Materials and Methods: Medical records of 22,651 patients with pulmonary tuberculosis admitted to Gulhane Military Medical Academia, Camlica Chest Diseases Hospital, Istanbul, Turkey from 1977 to 1999 were examined. Results: Of the 22,651 patients, $133(0.58 \%)$ died: 117 male and 16 female, mean age $41.5 \pm 20.7$ years. The mean length of hospital stay was $15.8 \pm 25.9$ days and it increased yearly $(p=$ 0.004). There was no significant difference in hospital mortality rate of tuberculosis within years. Forty-nine patients had chronic and/or far advanced tuberculosis, 36 of them had concomitant diseases. Thirteen patients had miliary and/or tuberculous meningitis, 3 multi drugresistant tuberculosis, another 3 had pneumothorax, and 2 empyema. These patients had significantly lower prognostic nutritional index than those patients who recovered from pulmonary tuberculosis $(p=0.025)$. Conclusion: Inhospital mortality rate of tuberculosis did not change in the last 23 years. We suggest that pulmonary
\end{abstract}

\begin{tabular}{ll}
\hline KARGER & ( ) 2003 S. Karger AG, Basel \\
Fax +4161306 1234 $347571 / 03 / 0121-0030 \$ 19.50 / 0$ \\
$\begin{array}{l}\text { E-Mail karger@karger.ch } \\
\text { www.karger.com }\end{array}$ & $\begin{array}{l}\text { Accessible online at: } \\
\text { www.karger.com } / \mathrm{mpp}\end{array}$
\end{tabular}

tuberculosis will continue to be a significant cause of death and therefore important health care problem for Turkey in the 21st century.

Copyright @2003S. Karger AG, Basel

\section{Introduction}

Tuberculosis (TB) is one of the oldest known diseases. Although the causal agent was known since 115 years ago and effective chemotherapeutic regimens for its treatment have existed for 53 years, TB continues to be a serious public health problem. Seven to 8 million people around the world become sick with TB each year. Nearly 1.6 million, 3 million and over a quarter of a million TB cases occur per year in sub-Saharan Africa, Southeast Asia and Eastern Europe, respectively. Developed countries have partly solved the problem of TB, but it is still a challenge for developing and undeveloped countries. Three million deaths occur annually from TB worldwide and it is known that $98 \%$ of these occur in underdeveloped or developing countries [1]. In Turkey, reports have shown that mortality rate has decreased from $55 / 100,000$ in the sixties to $2.3 /$ 100,000 in 1995 [2].

The decline in TB epidemic in this century had been largely due to improved living standards and, eventually, 
the availability and use of effective antituberculosis drugs. The annual number of new cases is expected to increase in the future. The main factors for this increase are demographic forces, population movements, the HIV epidemic and increasing drug resistance [3].

In this study, we have reviewed the medical records of patients diagnosed with pulmonary TB during a 23-year period (1977-1999) in order to establish mortality rate for TB in our hospital during this period.

\section{Material and Methods}

Medical records of 22,651 patients diagnosed with pulmonary TB at GATA Camlica Chest Diseases Hospital, Istanbul, Turkey from 1977 to 1999 were examined. The hospital serves as a referring center for military hospitals in the western part of Turkey. Tuberculosis Fighting Outpatient Clinic, Health Ministry, provides the necessary drugs for patients' treatment and subsequent follow-up.

All the patients had chest X-ray and sputum specimen examinations. The sputum procedures included direct Ziehl-Neelsen-stained smears and culture using Löwenstein-Jensen medium. When necessary, other specimens such as gastric lavage, bronchial lavage, pleural fluid were obtained to make secondary diagnosis. Laboratory examination of blood specimens including complete blood count, erythrocyte sedimentation rate, routine serum biochemical analysis and ELISA test for HIV antibodies (Abbott, HIV 1-2, USA) were also done.

The pulmonary TB was radiologically classified as minimal, moderately advanced and far advanced using a previously reported classification system [3]. Minimal lesions included those with slight to moderate density but did not contain demonstrable cavitation. The lesions involved a small part of one or both lungs, but the extent, regardless of distribution, did not exceed the volume of lung on one side that is present above the second chondrosternal junction and the spine of the fourth or the body of the fifth thoracic vertebra. Moderately advanced lesions were present in one or both lungs, but the extent did not exceed the following limits: disseminated lesions of slight to moderate density which extended throughout the total volume of one lung, or the equivalent in both lungs; dense and confluent lesions limited in extent to one third the volume of one lung; total diameter of cavitation, if present, was less than $4 \mathrm{~cm}$. Far advanced lesions were more extensive than 'moderately advanced'. All cases were treated according to WHO recommendations or guidelines [1].

The prognostic nutritional index $(\mathrm{PNI})$ was calculated as: $\mathrm{PNI}=$ $10 \times$ level of serum albumin $+0.005 \times$ peripheral number of blood lymphocytes as previously reported [4]. One hundred patients ageand sex-matched (91 male and 9 female) who recovered from pulmonary TB served as control for the calculation of PNI.

\section{Data Analysis}

Data are given as means \pm SD. For statistical analysis, we used Pearson's correlation test for evaluation of length of hospital stay and Student's $t$ test for comparisons of control and patients who died.

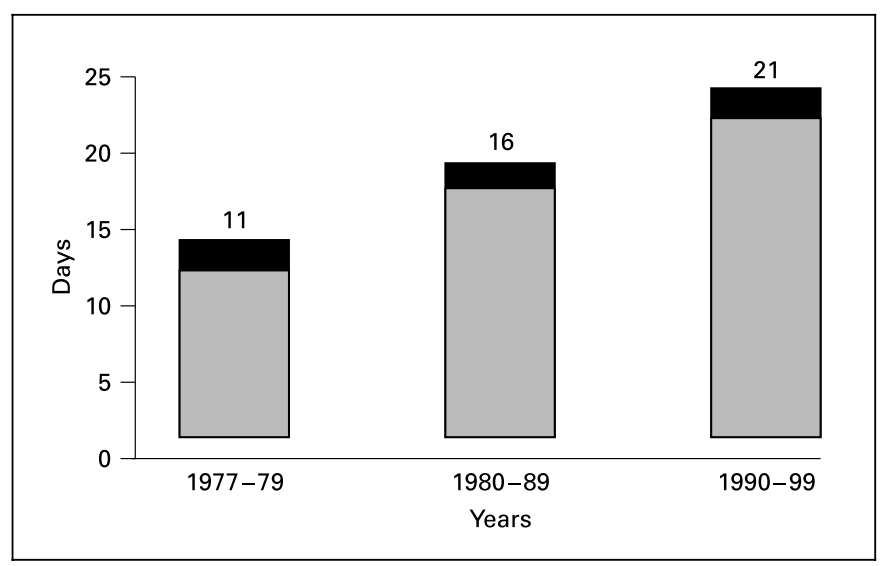

Fig. 1. Mean length of hospital stay of patients who died during three periods of analysis.

Table 1. Number of patients hospitalized for pulmonary TB and those dying from pulmonary TB in the last 23 years

\begin{tabular}{lll}
\hline Years & $\begin{array}{l}\text { Patients hospitalized } \\
\text { for pulmonary TB }\end{array}$ & $\begin{array}{l}\text { Patients who died } \\
\text { from pulmonary TB }\end{array}$ \\
\hline $1977-1979$ & 6,281 & 40 \\
$1980-1984$ & 7,322 & 45 \\
$1985-1989$ & 3,814 & 17 \\
$1990-1994$ & 2,497 & 17 \\
$1995-1999$ & 2,737 & 14 \\
Total & 22,651 & 133 \\
\hline
\end{tabular}

\section{Results}

During the 23-year study period, of the 22,651 patients, 133 (117 male and 16 female) died giving an overall inhospital mortality rate of $0.58 \%$ (table 1 ). However for periods 1977-1979 and 1995-1999, the mortality rates were 0.63 and $0.51 \%$, respectively. Mean age was $41.5 \pm 20.7$ years (range $20-83$ years). The mean length of hospital stay was $15.8 \pm 25.9$ days (range 1-168) and it increased yearly $(p=0.004)$ (fig. 1$)$. The PNI for the dead and survivors were $31.4 \pm 10.1$ and $44.75 \pm 5.1$, respectively. There was a significant difference in the mean length of hospital stay and PNI $(\mathrm{p}=0.025)$ between patients who died and survivors. Radiological appearance was moderately advanced or far advanced in patients who died (table 2). Since 1986, all the patients were HIV-negative. There was no significant difference in other routine laboratory investigations. 


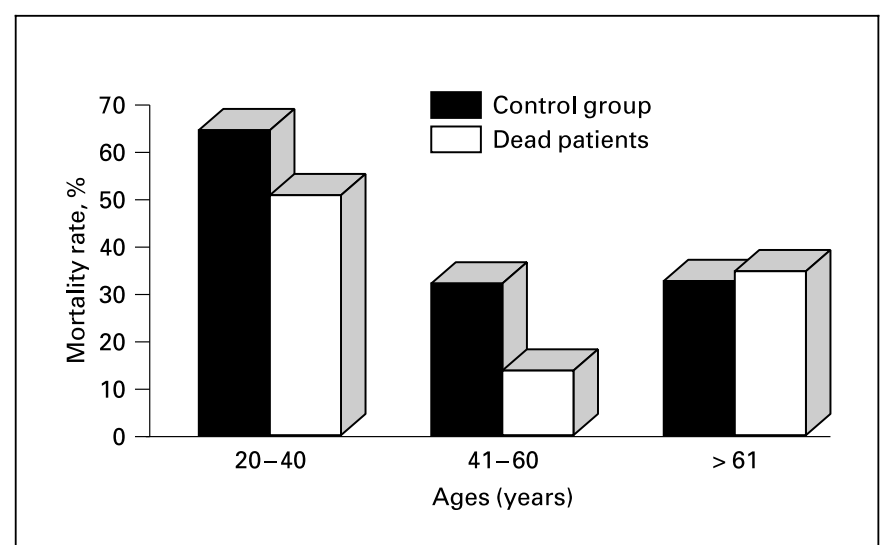

Fig. 2. Mortality rate based on age groups.

Table 2. General features of patients and controls

\begin{tabular}{lcc}
\hline Features & $\begin{array}{l}\text { Patients } \\
\text { who died }\end{array}$ & Controls \\
\hline Cases & 133 & 100 \\
Male & $117(87.9 \%)$ & $91(91 \%)$ \\
Female & $16(12.1 \%)$ & $9(9 \%)$ \\
Mean age \pm SD & $41.5 \pm 20.7$ & $38.7 \pm 25.8$ \\
Mean length of stay in hospital*, days & $15.8 \pm 25.8$ & $42.8 \pm 20.4$ \\
Radiological appearance* & & \\
$\quad$ Minimal & $0(0 \%)$ & $26(26 \%)$ \\
$\quad$ Moderate & $11(8.2 \%)$ & $37(37 \%)$ \\
$\quad$ Far advanced & $122(91.7 \%)$ & $36(36 \%)$ \\
PNI* & $31.4 \pm 10.1$ & $44.75 \pm 5.1$ \\
\hline
\end{tabular}

$* \mathrm{p}<0.05$.

Forty-nine patients had chronic and/or far advanced TB. Of 36 patients with concomitant diseases 10 had congestive heart failure, 8 diabetes mellitus, 7 chronic obstructive pulmonary disease or cor pulmonale, 3 bronchiectasis, 3 malignancies, 2 renal failures, 1 pneumoconiosis, 1 pemphigus vulgaris and 1 chronic psychosis. Thirteen patients had miliary and/or tuberculous meningitis. Three patients had multidrug-resistant TB. Three patients had penumothorax, and 2 patients had empyema.

The cause of death of the patients as recorded showed that most of the patients (112 patients) died from cardiorespiratory failure. Other causes of death included congestive heart failure (10 patients), cor pulmonale ( 7 patients), renal failure ( 2 patients), hemorrhage of the gastrointesti- nal system (1 patient) and complications of the lobectomy operation (1 patient).

Pulmonary TB was higher in younger and older people than middle-aged patients. Mortality rate of TB was higher in older patients (fig. 2).

\section{Discussion}

The observed hospital mortality rate indicates only deaths recorded in the hospital. This rate $(0.58 \%)$ was found to be low. In this study, patients who died after discharge from hospital were excluded. In developed countries, the mortality rate from TB is $1 / 100,000$ [5]. Previous study had shown that the mortality rate of TB is higher in Turkish men than women [6] consistent with the present observation. Mortality rate for TB is higher in older patients than in younger patients in developed countries as also observed in the present study. The diagnosis of TB was delayed in the older patients because of nonspecific symptoms $[7,8]$. The delay in diagnosis and treatment resulted in disease progression as therapy was initiated $26.3 \pm 18.4$ days later [9].

Previously, far advanced and delayed cases were admitted to the hospital and they died within a short period of time. However, in recent years, due to demographic changes in the population, delay in diagnosis has decreased, but within the same period, many patients had developed TB multidrug resistance, thereby causing difficulty with and treatment resulting in longer hospital stay. Apparently there is high drug resistance in Turkey; the primary and secondary drug resistance rates are 26.6 and $53.4 \%$, respectively [10].

It has been reported that malnutrition and hypoalbuminemia were related to fatality of TB in the Far East and Japan, respectively $[11,12]$. Malnutrition contributes to the morbidity of TB and may also contribute to mortality. In this and a previous study [12], patients with low PNI died earlier when compared to those with high PNI. It therefore seems that the patients need a good supply of nutrition during the treatment phase [13].

Alcoholism, diabetes mellitus, immune suppression, malnutrition, old age, and delayed diagnosis have been reported as important risk factors in TB mortality [1416]. HIV infection is also responsible especially in developed countries [17]. In Turkey, HIV infection is still not a risk factor [18]. Epidemiologic evidence indicates that HIV epidemic contributed substantially to the increased numbers of TB cases [19]. Mycobacterium tuberculosis enhances HIV replication and may accelerate the natural 
progression of HIV infection [19]. Mortality for TB is high, even among patients without multidrug resistance who are not known to be infected with HIV [20]. Extensive disease, low performance status, malnutrition, lymphocytopenia, previous chemotherapy, resistance to isoniazid and/or rifampicin, and poorer social circumstances seem to be risk factors for death due to TB [21]. Patients with lymphopenia, and especially when the value of CD4+ is less than $300 / \mathrm{mm}^{3}$, had poor prognosis [22, 23].

\section{Conclusion}

In Turkey, the inhospital mortality rate of TB is high; it did not change significantly during the study period. TB was an important cause of mortality in older patients and multidrug-resistant TB was a contributory factor. We suggest that pulmonary TB will continue to be a significant cause of death and therefore important health care problem for Turkey in the 21 st century.

\section{References}

1 WHO Report 2002: Global Tuberculosis Control, Surveillance, Planning, Financing. WHO/ CDS/TB/2002.295.

2 Web page of Turkish Ministry of Health. URL: http://www.verem.saglik.gov.tr.

3 Seaton A, Seaton D, Leitch AG: Crofton and Douglas's Respiratory Diseases, ed 4. Oxford, Blackwell Scientific Publications, 1989, pp 409-410.

4 Handa M: A nutritional and immunological investigation of patients with tuberculosis (abstract). Kekkaku 1994;69:463.

5 Friedman NL: Mycobacterium tuberculosis; in Bone RC (ed): Pulmonary and Critical Care Medicine. St. Louis, Mosby Year Book, 1993 , p 2.2 .

6 Caglayan B, Ozaydin N, Tumer O, Guler S: Mortality from tuberculosis in Heybeliada Chest Hospital, Turkey, (in Turkish). Heybeli Ada Tip Bulteni 1997;3:59-63.

7 de Meer G, van Geuns HA: Rising case fatality of bacteriologically proven pulmonary tuberculosis in The Netherlands. Tuber Lung Dis 1992; 73:83-86.

8 Naalsund A, Heldal E, Johansen B, Kongerud J, Boe J: Deaths from pulmonary tuberculosis in a low-incidence country. J Intern Med 1994 . 236:137-142.

9 Okutan O, Kartaloglu Z, Cerrahoglu K, Ilvan A, Tozkoparan E, Aydilek R: Time to beginning therapy and affecting factors in Turkish soldiers with pulmonary tuberculosis: An analysis of a Turkish Military Chest Diseases Hospital. Internet J Pulmonary Med 2001;2:1-6. URL:http://www.ispub.com/journals/IJPM/ Vol2N1/tbc.html
10 Tahaoglu K, Kizkin O, Karagoz T, Tor M, Partal M, Sadoglu T: High initial and acquired drug resistance in pulmonary tuberculosis in Turkey. Tuber Lung Dis 1994;75:324-328.

11 Murate T, Shimokata K, Watanabe A, Ichiyama S, Saito H, Yamori S, Nomura F, Iwahara T, Saki S, Nakanishi K: Chest roentgenogram classification and clinical parameters in patients with active pulmonary tuberculosis. Intern Med 1992;31:185-188.

12 Amishima M, Kishi F, Kamada F, Saito N, Hamada E, Hirai Y, Shinagawa M: Evaluation on the clinical background on early death in patients with pulmonary tuberculosis during the past five years (abstract). Kekkaku 1998;73: 727.

13 Macallan DC: Malnutrition in tuberculosis. Diagn Microbiol Infect Dis 1999;34:153-157.

14 Rao VK, Iademarco EP, Fraser VJ, Kollef MH: The impact of comorbidity on mortality following in-hospital diagnosis of tuberculosis. Chest 1998;114:1244-1252.

15 Zafran N, Heldal C, Pavlovic S, Vuckovic D, Boe J: Why do our patients die of active tuberculosis in the era of effective therapy? Tuber Lung Dis 1994;75:329-333.

16 Doherty MJ, Spence DP, Davies PD: Trends in mortality from tuberculosis in England and Wales: Effect of age on deaths from non-respiratory disease. Thorax 1995;50:976-979.
17 Borgdorff MW, Veen J, Kalisvaart NA, Nagelkerke N: Mortality among tuberculosis patients in The Netherlands in the period 1993-1995. Eur Respir J 1998;11:816-820.

18 Aktogu S, Yorgancioglu A, Cirak K, Kose T, Dereli SM: Clinical spectrum of pulmonary and pleural tuberculosis: A report of 5,480 cases. Eur Respir J 1996;9:2031-2035.

19 Prevention and Treatment of Tuberculosis among Patients Infected with Human Immunodeficiency Virus: Principles of Therapy and Revised Recommendations. MMWR 1998;47: $1-51$.

20 Pablos-Mendez A, Sterling TR, Frieden TR: The relationship between delayed or incomplete treatment and all-cause mortality in patients with tuberculosis. JAMA 1996;276: 1223-1228.

21 Sato A, Inoue T, Kurasawa T, Ikeda N, Nakatani K, Ikeda T, Yoshimatsu T: A clinical study of causes of death from active pulmonary tuberculosis with chemotherapy (abstract). Kekkaku 1998;73:733.

22 Barnes PF, Leedom JM, Chan LS, Wong SF, Shah J, Vachon LA, Overturf GD, Modlin RL: Predictors of short-term prognosis in patients with pulmonary tuberculosis. J Infect Dis 1988;158:366-371.

23 Pilheu JA, De Salvo MC, Gonzalez J, Rey D, Elias MC, Ruppi MC: CD4+ T-lymphocytopenia in severe pulmonary tuberculosis without evidence of human immunodeficiency virus infection. Int J Tuberc Lung Dis 1997;1:422426. 